\title{
Factores de riesgo de labio y/0 paladar fisurado en neonatos del Hospital Nacional Docente Madre - Niño San Bartolomé en el período 2000 al 2009
}

Risk factors of cleft lip and/or palate in neonates of Mother - Child National Teaching San Bartolome Hospital in the period 2000 to 2009

\section{Resumen}

El objetivo del estudio fue evaluar retrospectivamente los factores de riesgo, para las fisuras labiales y/o palatinas (FLP). Se seleccionó una muestra de 45 niños con fisura labial y/o palatina y a 45 niños recién nacidos sanos del Hospital Nacional Docente Madre Niño San Bartolomé entre enero del 2000 a diciembre del 2009 y a su respectiva madre biológica para evaluar retrospectivamente las condiciones en las que se llevó el embarazo en el primer trimestre de gestación. Se encontró que la prevalencia de fisura labial y/o palatina fue de $0.17 \%$, es decir, 1,7 por cada mil recién nacidos vivos. El género masculino (RRI 1,7), la edad materna mayor de 30 ańos y menor de 20 ańos (RRI1 8.4; RRI2 3,9), los antecedentes familiares de FLP (RRI 3,3), el número de gestaciones anteriores en cuanto a gestación única y segunda gestación frente a más de dos gestaciones (RRI1 4,6; RRI2 1,1) son factores de riesgo. Los antecedentes de infecciones, radiaciones y medicaciones durante el primer trimestre del embarazo no fueron factores de riesgo.

Palabras clave: fisura labial y/o palatina, prevalencia, factores de riesgo, recién nacidos.

\section{Abstract}

The aim of this study was to evaluate retrospectively the risk factors for cleft lip and/or palate. It was selected a sample of 45 children with a cleft lip and/or palate and 45 healthy newborns at Mother Child National Teaching San Bartolome Hospital from January 2000 to December 2009 and their respective biological mother to assess retrospectively the conditions under which this was formed during the first trimester of pregnancy. It was found that the prevalence of cleft lip and/or palate was $0,17 \%$ ie, 1,7 per thousand live births. The male gender (RRI 1.7), maternal age (RRI18.4; RRI23,9), family history of cleft lip and/or palate (RRI 3,3), number of previous pregnancies (RRI1 4,6; RRI2 1,1) are risks factors. The history of infections, radiation and medication during the first trimester of pregnancy were not found to be risks factors.

Key words: cleft lip and/or palate, prevalence, risk factor, newborns.

\section{Introducción}

Las deformidades del labio y paladar son malformaciones congénitas producidas por la no unión de los procesos nasales internos, maxilares y sus prolongaciones, que se presentan comúnmente en pacientes en todo el mundo, encontrándose en muchas investigaciones un promedio de incidencia de 1 en 1000 casos por ańo.

Existen investigaciones realizadas al respecto donde se concluye que estas malformaciones se presentan debido a un sinnúmero de factores que intervienen durante el desarrollo intrauterino; así en la actualidad se habla no sólo del carácter hereditario, sino también de la influencia de múltiples factores ambientales asociados a estas patologías. Se ha observado que las deformidades producidas en el labio y paladar se originan en las primeras siete semanas de vida en el útero, cuando se forma el labio y la premaxila.

En la actualidad, las fisuras de labio y paladar son entidades clínico-quirúrgicas bien definidas embriológica, anatomopatológica y fisiológicamente, de manera que su estudio y manejo exige realizar un abordaje multidisciplinario y complejo.

Es necesario resaltar que no existen estudios en neonatos en nuestro medio que pongan en evidencia los factores de riesgo para la generación de dicha malformación, así como de la prevalencia de la misma.

Todo ello motivó a realizar la presente investigación en las madres de los neonatos que tuvieron alguna malformación en el labio y paladar al nacer entre los ańos 2000 al 2009.

\section{Artículo Original}

\section{Marco Antonio Torres Durand ${ }^{1}$, Teresa Evaristo Chiyong $^{2}$}

\section{${ }^{1} \mathrm{CD}$, Práctica privada.}

${ }^{2}$ CD, Docente del Dpto. de Estomatología Preventiva y Social de la Facultad de Odontología de la UNMSM, Hospital Nacional Docente Madre - Niño "San Bartolomé”.

\section{Correspondencia:}

CD Marco Antonio Torres Durand

Av. Industrial 595. Cercado de Lima, Lima 1, Perú

Teléf.: 997-887-952

E-mail: marcotd69@hotmail.com

Fecha de recepción: 24-06-10

Fecha de aceptación: 24-03-11

\section{Material y método}

El método utilizado fue el de observación indirecta; es decir, se obtuvieron los datos de los neonatos y sus respectivas madres a través las historias clínicas. Se seleccionó al azar a un grupo de 45 neonatos vivos sanos y 45 con fisura labial y/o palatina en el mismo rango de tiempo con el fin de establecer el grupo control. La unidad de análisis fueron las historias clínicas del paciente nacido en el Hospital Nacional Docente Madre Niño "San Bartolomé" e historia clínica de la madre.

\section{Resultados}

De un total de 46254 neonatos registrados en el Hospital Nacional Docente Madre Niño "San Bartolomé", los pacientes nacidos con FLP son 82 que 
representan el $0,17 \%$ del total entre enero del 2000 a diciembre del 2009.

Se registró que un mayor número de casos correspondían al género masculino (26) que representa el $58.5 \%$ del total de la muestra. El género femenino fue el menor número de casos (19) que correspondían a un $41.5 \%$. En el grupo control, el mayor número de casos fue el grupo femenino (25) en un $55.5 \% \mathrm{y}$ después el masculino (20) en un $44.5 \%$.

De acuerdo a la clasificación propuesta por Kernahan y Stark, que se utilizó en el presente estudio, se encontró que el mayor número de casos correspondían al grupo III (27) que representa el $60 \%$ del total de la muestra. En segundo lugar según el número de casos correspondía al grupo I (13) que representa el $28 \%$ del total de la muestra. El menor número corresponde al grupo II (5) que representa el $12 \%$ del total de la muestra.

Se observó que el mayor número de casos en el momento de la gestación eran las madres mayores a 30 ańos de edad, considerado según el estudio el factor de más alto riesgo (RRI1 8,4) a diferencia del grupo control que el mayor número de casos corresponde a un rango de edad entre los 20 a 30 ańos. Un segundo lugar fue para las madres de menos de 20 ańos en el momento de la gestación lo que representa un riesgo moderado (RRI2 3,9). En el último lugar encontramos a las madres entre los 20 a 30 ańos de edad en el momento de la gestación considerado según el estudio de menor riesgo (Tabla 1 ).

De acuerdo a las infecciones en el primer trimestre del embarazo, se encontró
Infecciones del Tracto Urinario, otitis e infecciones respiratorias (9), que representa el 19,52\%, el resto de madres no presentó ninguna infección registrada en la historia clínica (36), que representa el $80.48 \%$. En el grupo control se encontró que tuvieron infecciones (17) en un $37,8 \%$, a diferencia de las que no tuvieron (28), en un 62,2\%. Se obtuvo un Riesgo Relativo Indirecto de 0,4 , no considerándose un factor de riesgo.

Se observó que hubieron madres de neonatos con FLP que ingirieron medicamentos durante el primer trimestre del embarazo (8) tales como diazepam, fenitoína, nitrato de miconazol, entre otros, en un $18.5 \%$, mientras que las que no consumieron medicamentos (37), según lo recolectado de las historias clínicas, representan el $81.5 \%$. En el grupo control se encontró que sí consumieron medicamentos (10) en un $22.2 \%$ y las que no (35) en un $77.8 \%$. El Riesgo Relativo Indirecto obtenido fue 0.7 , no considerándose un factor de riesgo.

Las madres que se irradiaron durante el primer trimestre de gestación (9) representan el $19.5 \%$. En cuanto al grupo control se encontró que de las que sí estuvieron expuestas (13) representan el $28.8 \%$ y de las que no estuvieron expuestas (32) que es el $71.2 \%$. Se obtuvo un Riesgo Relativo Indirecto de 0.6 , no considerándose un factor de riesgo.

Se observó diferencias entre los grupos de estudio y control respecto la cantidad de gestaciones (Tabla 2).

\begin{tabular}{lcccc}
\hline \multicolumn{1}{c}{ Grupo } & \multicolumn{2}{c}{ FLP } & \multicolumn{2}{c}{ Control } \\
\hline \multicolumn{1}{c}{ Rango etario } & $\mathbf{N}^{\circ}$ & $\mathbf{\%}$ & $\mathbf{N}^{\circ}$ & $\%$ \\
Menores de 20 años & 14 & $31.1 \%$ & 10 & $22.2 \%$ \\
Entre 20 - 30 años & 10 & $22.2 \%$ & 28 & $62.2 \%$ \\
Mayores de 30 años & 21 & $46.7 \%$ & 7 & $15.6 \%$ \\
Total & $\mathbf{4 5}$ & $\mathbf{1 0 0 \%}$ & $\mathbf{4 5}$ & $\mathbf{1 0 0 \%}$ \\
\hline
\end{tabular}

Tabla 1. Edad de las madres de los nińos con fisura labial y/o palatina y grupo control nacidos en el Hospital Nacional Docente Madre Nińo "San Bartolomé” entre enero del 2000 a diciembre del 2009.

\begin{tabular}{lcccc}
\hline & \multicolumn{2}{c}{ FLP } & \multicolumn{2}{c}{ Control } \\
\hline $\boldsymbol{N}^{\circ}$ Gestaciones & $\mathbf{N}^{\circ}$ & $\%$ & $\mathbf{N}^{\circ}$ & $\%$ \\
Gestación única & 22 & $48 \%$ & 8 & $18 \%$ \\
Gestación 2 & 13 & $28 \%$ & 20 & $44,5 \%$ \\
Gestación más de 2 & 10 & $24 \%$ & 17 & $37,5 \%$ \\
Total & $\mathbf{4 5}$ & $\mathbf{1 0 0 \%}$ & $\mathbf{4 5}$ & $\mathbf{1 0 0 \%}$ \\
\hline
\end{tabular}

Tabla 2. Gestaciones anteriores de las madres de nińos con FLP y grupo control del Hospital Nacional Docente Madre Niño “San Bartolomé” entre enero del 2000 a diciembre del 2009.

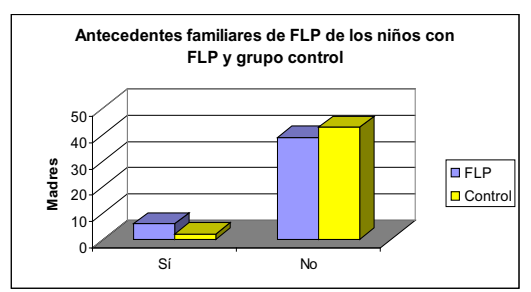

Fig. 1. Se observó mayor presencia de antecedentes en el grupo con la patología de fisura labial y/o palatina

\section{Discusión}

Con respecto al Factor de Riesgo "Edad materna en el primer periodo gestacional" se encontró riesgo relativo RRI entre mayores de 30 años, frente las de 20 a 30 años de 8,4, lo que significa que sería un factor predisponente; es decir, una madre mayor a 30 años tiene 8,4 más riesgo de tener un niño con fisura labial y/o palatina que una madre entre los 20 a 30 ańos, esto coincide con la literatura, ya que existe mayor riesgo en una madre mayor a 30 años en el momento de la concepción a diferencia de una madre de entre los 20 a 30 años que es considerada una edad ideal para la fertilidad. No concuerda con lo encontrado por Sotomayor y Gutarra (2004) que la mayor cantidad de casos se presenta no a una edad muy avanzada, sino a una edad intermedia entre 21-30 años ${ }^{1-3 .}$

A su vez, se encontró un segundo RRI entre las menores de 20 años frente a las de 20 a 30 ańos, de 3,9, lo que significa que sería un factor predisponente; es decir que una madre menor a 20 años tiene 3,9 más riesgo de tener un niño con FLP que una madre de entre los 20 a 30 años, esto también coincide con la literatura ya que a una edad muy temprana existe riesgo de que el neonato padezca de alguna patología ${ }^{(1)}$. Estos resultados concuerdan con lo encontrado por Sepúlveda y col. (2008), quienes concluyeron que las de mayor riesgo eran las pacientes menores a 20 años ${ }^{2}$.

En cuanto a las infecciones durante el primer trimestre gestacional se encontró un RRI de 0.4 , lo que significaría en el estudio que sería un factor protector no concordando con la literatura que manifiesta que las infecciones durante el primer trimestre sí son un factor causal de algún tipo de alteraciones en la formación del neonato durante el primer trimestre de gestación. A su vez estos resultados serían bajos comparándolo con lo encontrado por Sacsaquispe (2004) en la mitad de la muestra de los casos ${ }^{(4)}$ y estadísticamente similar a lo encontrado por Sotomayor y Gutarra 
(2004), sólo el $17,6 \%$ de su población tuvo infección durante el primer trimestre del embarazo. ${ }^{3}$

Respecto a la medicación durante el primer trimestre gestacional se encontró un RRI de 0,7, lo que nos estaría indicando que no sería un factor de riesgo. Los resultados de porcentaje de madres con medicación son relativamente menores a lo encontrado por Sacsaquispe (2004), que un tercio de la población sí consumió medicamentos en el primer trimestre de la gestación ${ }^{(4)}$, así como con el estudio de Sotomayor y Gutarra (2004), donde se observa que la tercera parte de la muestra registra antecedente de ingesta de medicamentos ya sea prescrita por un médico o automedicándose. ${ }^{3}$

En cuanto a "Radiaciones durante el primer trimestre gestacional" como factor de riesgo se encontró un RRI de 0,6 lo que nos estaría indicando que sería un factor protector, tampoco concuerda con la literatura que dice que las exposición a radiaciones durante el primer trimestre gestacional, sin una debida protección, ocasionaría algún tipo de alteraciones en el feto durante el primer trimestre de gestación. ${ }^{5}$

Respecto a los "Antecedentes familiares de FLP” se encontró un RRI de 3,3 lo que sí nos estaría indicando que sería un factor predisponente; es decir, que un neonato con antecedentes familiares de FLP tiene 3,3 más riesgo de tener fisura labial y/o palatina que un neonato sin estos antecedentes. Esto coincide con lo encontrado por Sacsaquispe (2004) y Sotomayor y Gutarra (2004); y estadísticamente menor a lo encontrado por Sepúlveda y col. (2008). 4,3,2

En cuanto al Factor de Riesgo "Gestaciones anteriores" se encontró un RRI entre Gestación única frente a Gestación más de 2 de 4,6, lo que nos estaría indicando que sería un factor predisponente; es decir, una madre con gestación única o "primeriza" tiene 4,6 más riesgo de tener un niño con fisura labial y/o palatina que una madre con más de 2 gestaciones anteriores, a su vez también se encontró un RRI entre Gestación Segunda vs. Gestación más de 2 de 1,1, lo que significa que también sería un factor predisponente; es decir, que una madre en su segunda gestación tiene 1,1 más riesgo de tener un nińo con FLP que una madre con más de 2 gestaciones anteriores, esto coincide con la literatura ya que normalmente, y más aún en una realidad como la de nuestro país, se relaciona el término "primeriza" con "edad temprana" en el momento de la fecundación, y tomando en cuenta que se trata de un organismo aún poco maduro tiene cierto riesgo en concebir un neonato con algún tipo de patología. ${ }^{6}$ Estos resultados coinciden también por lo encontrado por Sotomayor y Gutarra (2004), donde concluyen también que la gran mayoría de los niños con algún tipo de fisura ocupan el primer lugar en el orden de nacimiento (fratría). ${ }^{3}$

\section{Conclusiones}

La prevalencia de fisura labial y/o palatina en neonatos fue del $0,17 \%$ es decir de 1,7 por mil recién nacidos vivos.

La edad materna en el momento de la concepción, los antecedentes familiares de fisura labial y/o palatina y el número de gestaciones anteriores son factores de riesgo para la concepción de niños con fisura labial y/o palatina.

En la presente investigación, las infecciones en el primer trimestre gestacional, la medicación en el primer trimestre gestacional, sea esta prescrita o automedicada, y la radiación en el primer trimestre de gestación no fueron un factor de riesgo.

\section{Referencias bibliográficas}

1. Mencos I, Cebreros E, Cespedes C, Aranibar A, Rosing L, Garbin
L, Alcañiz L. Efecto de la edad materna en el embarazo. [Consultado 20 de Mayo de 2010] Recuperado de: http://espanol.babycenter.com/ pregnancy/salud_prenatal/edad_y_ embarazo/\#axzz1VqLQt42d

2. Sepúlveda G, Palomino H, Cortés J. Prevalencia de fisura labiopalatina e indicadores de riesgo: Estudio de la población atendida en el Hospital Clínico Félix Bulnes de Santiago de Chile. Rev Esp de Cirug Oral y Máxilofac 2008; 30(1):17-25 Recuperado en: http://scielo.isciii.es/ $\mathrm{pdf} / \mathrm{maxi} / \mathrm{v} 30 \mathrm{n} 1 /$ caso $1 . \mathrm{pdf}$ d o i : $10.4321 /$ S 1130 05582008000100002

3. Sotomayor J, Gutarra L. Factores de riesgo en el embarazo para la presencia de fisuras labio máxilo palatinas. Odontol. Sanmarquina 2004; 8(1): 17-24

4. Sacsaquispe S, Ortiz L. Prevalencia de labio y/o paladar fisurado y factores de riesgo. Rev Estomatol Herediana 2004; 14(1-2):54-58.

5. Agencia para sustancias tóxicas y el registro de enfermedades Departamento de Salud y Servicios Humanos. Atlanta. GA 30333 USA. Posibles efectos de la exposición a la radiación en la salud de los bebés que están por nacer. [Consultado:abril 2010 Internet"] http://www.atsdr.cdc.gov/es/phs/ es_phs158.pdf

6. Zarante I, Castillo M, Garcia N, Suárez F, Gutiérrez C. Análisis clínico epidemiológico de factores asociados a malformaciones congénitas ECLAMC- Hospital Universitario San Ignacio Junio-Diciembre del 2001. Pontificia Universidad Javeriana. Disponible en: http://med. javeriana.edu.co/publi/vniversitas/ serial/v43n2/0031\%20ANALISIS. PDF. 